\title{
La historiografía económica sobre el Valle del Cauca: siglos XIX-XX
}

\author{
Julio César Zuluaga
}

\author{
¿No es bueno acaso que la historia sea ante todo una \\ descripción, una simple observación, una clasificación sin \\ excesivas ideas preconcebidas? \\ Ver, mostrar, en eso consiste la mitad de nuestra tarea. Y ver, \\ si es posible, con nuestros propios ojos. \\ Fernand Braudel
}

\begin{abstract}
This article tackles, from a quantitative perspective, the economic historiography in el Valle del Cauca for the nineteenth and twentieth -centuries, with the aim of presenting a preliminary approximation to a historiographical balance on this topic. Through the analysis of aspects, such as the type and frequency of publications, the authors, their nationality and disciplines represented, the themes developed, the chronology and the spaces studied, this article will access the level of development that this historiographical subfield has achieved in the study and analysis of the regional economy.
\end{abstract}

\section{Introducción}

Como comenta Raphael Samuel, a propósito de las relaciones entre historia y teoría:

Los historiadores no son dados, al menos en público, a la introspección sobre su trabajo y, exceptuando los momentos solemnes, como las conferencias inaugurales, por ejemplo, evitan la exposición general de sus objetivos [...] Ante todo (los historiadores) se consideran a sí mismos como investigadores, oyentes atentos y observadores minuciosos, guiados por una simpatía imaginativa hacia el pasado 
y una percepción intuitiva de sus vestigios manuscritos y materiales (Samuel, 1984 : 48).

La escritura de la historia colombiana, a excepción de algunos trabajos, padece esta misma característica. Al introducirnos en el terreno de la reflexión disciplinar acerca de la historiografía, esto es, la producción escrita sobre temas y procesos históricos (Fontana, 1999: 9) acaecidos en el país, nos encontramos con un panorama poco alentador. Escasos trabajos promueven una de las labores esenciales y no menos importantes del historiador: reflexionar y pensar sobre la historiografía.

Para avanzar y renovar el grado de investigación histórica en el país, es necesario no solo la revisión de los rumbos que ha tomado la escritura de la historia en su labor de reconstruir, explicar e interpretar la historia sino, también, el análisis de las relaciones que se producen por la concurrencia de los historiadores y sus obras en el campo historiográfico nacional. De esta manera "la historia parece verse obligada a mirarse al espejo, aplicando para su propio autoexamen y estudio todas las herramientas que se han ido desarrollando y perfeccionando en los últimos ciento treinta años" (Aguirre, 2004 : 144). Necesidad hoy impostergable que llama a los historiadores a impulsar y consolidar el estudio y análisis de la historia de la historiografía. En este sentido, como comenta Carlos Aguirre Rojas:

[Un] balance del estado de los estudios históricos hoy es pertinente porque, lejos de ceder a las fáciles tentaciones de los balances "finiseculares" y "finimilenarios" hoy tan a la moda, permite más bien reivindicar la necesaria práctica de estos estudios de autoexamen de la historia como una práctica cotidiana y permanente, práctica que siendo una de las tareas esenciales de la rama denominada "historia de la historiografía" ha sido muy poco y muy desigualmente cultivada dentro de las historiografías latinoamericanas y europeas, desarrollándose de manera solo marginal o episódica (2004 : 135 136).

De esta manera, es acuciante la importancia de instaurar, como ejercicio cotidiano y reiterado, el cultivo sistemático de análisis de la historia de la evolución y los contextos específicos del propio decurso del pensamiento historiográfico, la necesidad de colmar esta laguna persistente de los estudios históricos locales, que es el vacío padecido, la ausencia de una línea constante de reflexión disciplinar; para esa labor, los historiadores cuentan con una herramienta analítica e investigativa indispensable: el balance historiográfico.

Si la historiografía es la escritura de la historia (Aróstegui, 1995), es decir, el resultado de la investigación histórica, un balance es la discusión acerca del resultado de esas investigaciones realizadas dentro de las historiografías sectoriales. 
El termino "discusión" debe ser entendido en su definición más amplia: discutir sobre la manera como los historiadores han construido y presentado las investigaciones en el espacio social, señalando la metodología empleada, tendencias y escuelas historiográficas apropiadas, problemas abordados, material empírico analizado, entre otros aspectos concernientes al estudio del campo científico y a los contextos de producción y recepción (Véase Bourdieu, 2003: 1999). Un balance, si bien atiende al enfoque sincrónico, se preocupa, ante todo, del punto de vista diacrónico. En este sentido, tiene como objeto el análisis de la producción historiográfica en su desenvolvimiento temporal y espacial, la historia de la historiografía, la evolución del pensamiento historiográfico.

Siguiendo estas reflexiones, este artículo trata el problema en torno a la forma en que se ha abordado y reconstruido, desde una perspectiva cuantitativa, la investigación sobre la historia económica vallecaucana entre los siglos XIX y XX. El objetivo del artículo es construir un balance de la historiografía económica sobre la región del Valle del Cauca entre los siglos XIX y XX. La pregunta central que se desarrolla es: ¿Cómo ha analizado y problematizado, la historiografía colombiana, ${ }^{1}$ el estudio de la economía del Valle del Cauca durante los siglos XIX y XX? ¿Cuál es el estado cuantitativo de la escritura de la historia económica sobre la región del Valle del Cauca siglos XIX-XX? Como derivación de este interrogante, se intenta responder a una serie de preguntas como ¿Qué temas, siglos, subperiodos, espacios conocemos? ¿Qué autores, disciplinas, nacionalidades confluyen en el estudio de la historia económica del Valle del Cauca? Para dar respuesta a estas preguntas se realiza una descripción cuantitativa en torno a unas variables construidas y seleccionadas de las publicaciones y se esbozan algunas hipótesis que permitan elaborar una idea general.

La dinámica económica del Valle del Cauca durante los siglos XIX y XX ha sido poco estudiada por el campo historiográfico regional y nacional. Esto contrasta con el papel fundamental que jugó la región como centro productivo y comercial durante fines del siglo XIX y todo el siglo XX. El desenvolvimiento de la escritura de la historia económica se caracteriza por un auge inicial al

1 Cuando se habla de historiografía colombiana se hace referencia -como señala Jaime Eduardo Londońo- "al 'grupo heterogéneo' de historiadores profesionales, regularmente vinculados a universidades oficiales y privadas, a entes gubernamentales o a organizaciones no gubernamentales. [...] Desde sus orígenes, en la década del 60 del siglo XX, hasta el presente, se pueden identificar tres o cuatro generaciones de historiadores. Los miembros que integran este 'grupo', no están unificados en torno a una comunidad académica consolidada o suficientemente estructurada a su respectivo paradigma. Por lo tanto, no tienen criterios claramente establecidos respecto a los temas de estudio, a los conceptos y a la metodología de investigación. La ausencia de líneas de trabajo unificadas se refleja en la existencia de tendencias de investigación de diversa índole, que no están necesariamente asociadas a paradigmas específicos. Por el contrario, en la mayoría de los casos el acercamiento se realiza de manera pragmática. Encontramos enfoques que oscilan desde el historicismo hasta las orientaciones mas recientes de la historia cultural. Esta gama de tendencias es 'renovada' de acuerdo a los cambios de la historiografía mundial." (Londoño, 2002: 221). 
presentarse un inusitado crecimiento de este tipo de estudios durante los decenios de 1970-1980 y parte de 1990, investigándose los más variados problemas, temas, periodos históricos y espacios. Auge que comienza a debilitarse hacia la última década del siglo XX y a estancarse y retroceder hacia mediados de la del 2000. La razón, una débil consolidación de un campo científico especializado, regular y permanente, con líneas de investigación claras, dedicado a la investigación y análisis de la historia económica regional.

El análisis evidencia un rápido y pronunciado desaceleramiento en el ritmo de producción y publicación desde los últimos cinco o seis años, un decaimiento en la investigación como producto del alejamiento de los historiadores y demás científicos sociales de los temas y problemas de la historia económica y al retroceso que se observa en la consolidación de este tipo de estudios. Esto lleva a postular que los estudios sobre la historia económica del Valle se encuentran transitando por un periodo de "crisis" o estancamiento relativo. Además, en torno a la forma en que se está abordando dicho estudio, es evidente la poca preocupación que los científicos sociales manifiestan por la producción de conocimiento histórico de la economía regional; crisis que puede ser pasajera o que puede pronunciarse aún más como resultado de la falta de una sólida consolidación e institucionalización de esta área de estudio, de la ausencia de un campo historiográfico con líneas de investigación fortalecidas que permitan guiar la investigación histórica en este terreno y lograr un desarrollo positivo en cuanto al conocimiento de la historia económica se refiere.

Para estos propósitos se han construido una serie de tablas que permiten el análisis y la presentación de la historiografía económica seleccionada, la cual consiste en un registro de 132 publicaciones entre libros, artículos y capítulos de libros. ${ }^{2}$ El texto se encuentra dividido en tres grandes acápites. El primero delimita el concepto de historiografía económica y describe el proceso de surgimiento de los estudios sobre historia económica regional. El segundo, subdividido en cinco secciones, analiza aspectos que tienen que ver con la forma y la evolución que ha adoptado la escritura de la historia económica y aspectos del campo historiográfico. En la primera sección se realiza un análisis de los tipos de publicación con el que se da cuenta la extensión que ha tomado el resultado de las investigaciones; en la sección periodos de publicación se reconstruye el ritmo de publicación -y por ende el de investigación-, para esbozar algunas tendencias del desenvolvimiento de la historiografía económica; en la de autores se presenta una idea sobre la composición del campo de la historiografía económica al mostrar la

2 No son tenidas en cuenta las tesis de pregrado y posgrado. Recientemente ha sido publicado un libro de historia empresarial, titulado MAC: Empresa y familia, medio siglo de energía -Universidad Icesi, Cali, 2007coordinado por Jaime Eduardo Londoño Motta, donde se reconstruye la historia de una empresa del Valle del Cauca (ciudad de Cali) en el siglo XX, el cual no incluimos en las posteriores tablas. 
cantidad de autores dedicados a este tipo de estudios; en las secciones de disciplina y nacionalidad de autores se esclarecen las disciplinas que convergen en el estudio de la historia económica y el nivel de atención que recibe dicha historia por parte de los investigadores extranjeros y nacionales. El tercer acápite, dividido en tres secciones, determina el conocimiento que se posee de algunos aspectos de la historia económica regional. En la sección sobre las temáticas se da cuenta de las áreas cubiertas -y no cubiertas- de la historia económica, al indicar la cantidad de publicaciones; en la sección de siglos se describen los periodos -siglos XIX, XX, o XIX y XX-abordados por la investigación; la sección de espacios ubica las localidades -municipios, pueblos, zonas- estudiadas. El escrito cierra con unas conclusiones donde se recogen algunas ideas importantes en torno a la escritura de la historia económica de la región y su posible evolución.

El propósito no es evaluar el estado de conocimiento sobre cada tema, espacio o periodo, pues para ello seria necesario un examen detallado de cada una de las publicaciones, donde se clarifiquen, analicen las hipótesis, los problemas y contenidos de las investigaciones, tampoco abordar de manera exhaustiva los contenidos de las investigaciones, sus marcos de referencia teóricos o el grado de verificación y plausibilidad de las hipótesis, sino un examen de cobertura, similar al realizado por Jesús Antonio Bejarano (1994), a partir del número de estudios, con el fin de llamar la atención sobre aquellas temáticas o periodos, subperiodos o espacios aún no cubiertos por la investigación y la historiografía económica.

\section{Surgimiento de la historiografía económica regional}

La historiografía sectorial conocida como "historia económica" es definida en este trabajo como la producción -el resultado de la investigación histórica, el conocimiento producido, la escritura- sobre procesos y fenómenos económicos ocurridos en el transcurso del tiempo y el espacio; se ocupa del estudio de los fenómenos y procesos históricos catalogados como económicos, de acuerdo a determinados paradigmas o enfoques teóricos. La historiografía económica es el conocimiento producido sobre los procesos y fenómenos económicos que están determinados en una realidad social concreta, a partir de unas bases teóricometodológicas; en este sentido es preciso decir que no se la puede identificar, como hacen la mayoría de los economistas, con los mismos procesos económicos reales - por eso ellos terminan tomando una cosa por otra, confunden la teoría con lo que es su objeto de estudio o como decía Marx en sus criticas a Hegel: "pasan perfectamente, sin ningún cuidado, de las cosas de la lógica a la lógica de las cosas"-; la investigación histórico-económica debe solo aspirar, mediante el 
conocimiento científico, a explicar y comprender el funcionamiento económico de determinada sociedad, produciendo una serie de hipótesis y tesis que traten de dar cuenta lo más plausiblemente de su funcionamiento histórico-económico. Se subraya así la diferenciación -epistemológica, conceptual y analítica- entre el discurso científico -el conocimiento producido por un sujeto- y los procesos económicos que tienen lugar efectivamente en el mundo social -el objeto de conocimiento-.

Para el caso de los estudios historiográficos sobre la economía de la región, los limites claros y diferenciados entre historiografía económica y demás historiografías sectoriales han sido difusos en cuanto a objeto de estudio se refiere, debido a que en muchos de los trabajos las temáticas políticas, sociales y hasta culturales han acompañado al desarrollo de la historiografía económica, al punto que para muchos estudios es difícil determinar si es una investigación sobre historia económica, política o social. Por ende, una historiografía económica en el sentido fuerte del concepto, como ha sido concebida y desarrollada en otros campos intelectuales, en términos de desarrollo relativamente profesionalizado y especializado, aislado y autónomo del ámbito o la esfera de lo económico no ha tenido fuerte presencia en los estudios sobre la región. ${ }^{3}$ A este respecto, alguien podría advertir esta situación como un defecto dentro de la historiografía sectorial; sin embargo, hemos de advertir que este traslape, si es bien aprovechado y desarrollado de manera ingeniosa, puede ser una fuerte herramienta para el avance de los estudios historiográficos sobre la región.

La escritura de la historia económica sobre el Valle del Cauca es un campo aún muy joven en el conjunto de los estudios historiográficos sobre la región. Con solo unas décadas de surgimiento y desarrollo, esta historiografía sectorial ha tomado importancia y legitimidad entre los historiadores profesionales y demás científicos sociales que se dedican a la investigación regional, y una centralidad fundamental para el estudio, comprensión y explicación de determinados procesos históricos de la región.

El espectro de este tipo de estudios surgió a mediados de la década de 1960 y en el transcurso de la de 1970, cuando comenzaron a realizarse las primeras investigaciones y publicaciones sobre la economía de la región, las cuales: "[...] pueden ser complementadas con los diversos estudios relacionados con la historia social, lo que podríamos ubicar en la antigua noción de historia económica y social que permitió el surgimiento de este tipo de estudios para esta región del país" (Valencia, 2001 : 85). La historiografía económica sobre la

3 Esta situación puede estar empezando a cambiar en el contexto nacional al arribo de tendencias historiográficas basadas en el uso "riguroso" de la teoría económica -económetria, Clíometria- cuando no son lo suficientemente críticas en sus acepciones generales sobre el concepto de lo "económico" y sus relaciones con la totalidad social. 
región se comienza a consolidar en la década de 1970, una década posterior a su surgimiento en el conjunto de los estudios historiográficos del país, gracias a la influencia y arribo de nuevas corrientes historiográficas que impulsaban una pretendida nueva concepción en el estudio de la historia, y que pretendían una ruptura radical con las antiguas temáticas, formas y métodos de investigar y concebir la historia. Este arribo se dio mediante la influencia de Jorge Orlando Melo y Germán Colmenares, quienes realizaron sus estudios de postgrado en el exterior trayendo consigo las perspectivas teóricas que aprendieron en estos estudios. Paralelo a este proceso, la conformación de un núcleo de historiadores formados en instituciones universitarias, y no aficionados como predominaba hasta ese entonces, contribuyo a que la ruptura entre la forma tradicional de reconstruir la historia de la región se diera de una manera más acentuada y a que, crecientemente, se consolidara y legitimara la Nueva historia que, respecto a las temáticas y enfoques de la historiografía practicada por las academias de historia que se centraban fundamentalmente en la historia política y de las elites, y en los periodos de la independencia y la era republicana, se iba a dirigir fundamentalmente hacia el estudio de la historia económica, social, y cultural, centrada en las grandes masas de población, y a concentrarse principalmente en el periodo de la conquista, la colonia y en la segunda mitad del siglo XIX.

Fundamental para este proceso de surgimiento y consolidación de la historiografía económica sobre el Valle del Cauca fue la creación del Departamento de Licenciatura en Historia de la Universidad del Valle en el año de 1977, que indudablemente -según Alonso Valencia Llano-:

\section{[...] fue conocido como uno de los primeros en abordar la historia regional gracias a la labor de historiadores como Germán Colmenares y Jorge Orlando Melo, dos figuras que por su formación -generalmente en universidades extranjeras- y por su enorme capacidad de trabajo, concentraban todos los desarrollos y avances historiográficos que en la Universidad se daban y que fluctuaban entre estudios monográficos regionales e investigaciones de un carácter más amplio (2001: 78).}

Estos autores fueron quienes más abrieron el camino para la consolidación de una historiografía económico-social centrada en la región, junto con un pequeńo grupo de historiadores -y estudiantes de pregrado y postgrado- que se dedicaron al estudio de diversos aspectos y problemas que constituyen la base sobre la cual se desarrolló posteriormente el conocimiento historiográfico de la economía vallecaucana.

Bajo la influencia de Germán Colmenares y Jorge Orlando Melo, un grupo de profesores del Departamento de Historia -Edgar Vásquez, Luís Valdivia, y 
Jorge Salcedo- fundaron en el año de 1979 una publicación de difusión conocida como Historia y espacio. Revista de estudios históricos regionales, la cual contó con una orientación en realidad muy amplia para el desarrollo de la investigación que apenas se consolidaba, pero que estaba dirigida centralmente, según sus directores, al desarrollo de la historiografía económica y social, orientada:

\section{[...] hacia temas de interés regional, dentro del marco de la historia económica y social, aún cuando muchos de estos trabajos tienen principalmente un carácter empírico -material de archivos, estadística histórica, historias descriptivas, urbanas y rurales- pensamos que es fundamental considerar aquí la reflexión teórico metodológica que se considera pertinente (Vásquez, et al., 1977: 7).}

Historia y espacio, si bien fue una revista amplia -y generalmente constantedonde se difundieron investigaciones sobre historia política, social y cultural de los profesores del Departamento, fue -y todavía es- lo más cercano a una publicación o empresa editorial que se ha propuesto la creación de una revista de historiografía económica sobre la región. Además, como comenta Alonso Valencia Llano: "fue esta revista la que más estimuló la investigación histórica regional; por otra parte, las temáticas abordadas y la forma de hacerlo sirvieron para que muchos estudiantes de la época tuviéramos modelos de investigación que serían fundamentales en nuestro desarrollo futuro" (Valencia, 2001 : 79). Otras revistas y centros de investigación, como Región y el Boletín Socioeconómico del Centro de Documentación e Investigación Socioeconómica CIDSE, también se han convertido en la práctica en impulsores de la investigación y publicación de obras sobre la historia económica regional.

Esfuerzos orientados a sostener un proyecto como el que se propusieron los directores de Historia y espacio -así no lo hayan logrado- no se avizoran en el mediano tiempo, aún más cuando se evidencia una baja en el ritmo de publicaciones e investigación sobre historia económica, la debilidad o ausencia de un campo de profesionales dedicados al desarrollo de la historiografía económica y la falta de proyectos sólidos de creación de líneas de investigación en este campo. Esta revista, superando esta propuesta inicial, no publicó ni se dedico exclusivamente a los estudios de historia económica y social, sino también a investigaciones sobre la geografía, la etnohistoria, la política o el desarrollo empresarial del Valle del Cauca, y otras regiones de latinoamericanas. Desde su perspectiva e influencias teóricas e historiográficas, de acuerdo al clima intelectual del momento, la revista se dedicaba a la investigación de problemas, temáticas y periodos no tenidos en cuenta por la historiografía de las academias de historia, insertándose de esta manera en el proyecto liderado por algunos historiadores del país en lo que se llamo la Nueva historia. Este trabajo lo realizaba pretendiendo 
enmarcarse entre una historiografía de arraigo marxista oficial -con acento soviético-, una empirista de corte anglosajón, y al tiempo por la influencia historiográfica de la esuela de Annales. ${ }^{4}$

Básicamente fue durante la década de 1970 y 1980 cuando, a la luz del Departamento de Historia de la Universidad del Valle -y a algunos profesionales de disciplinas vecinas y de otras regiones del país-, la historiografía económica sobre la región presentó sus mayores esfuerzos y desarrollos en la consolidación de un campo de estudio de la historia económica, ya que fue aquí donde se intentó generar un centro de investigadores dedicados al cultivo de esta área de estudio que, sin embargo, fue muy efímero y poco consolidado. En la década de 1990, con la promoción de la Maestría en Historia Andina del Departamento de Historia de la Universidad del Valle, desde la cual se desarrollaron algunas investigaciones sobre historia económica de la región, se siguieron realizando esfuerzos, que no superan los logros obtenidos en el transcurso de las dos décadas anteriores. Si bien la Universidad del Valle sigue siendo una institución que contribuye al desarrollo de la investigación en historiografía económica, y en general en historiografía sobre la región, en las décadas de 1990 y lo que va del 2000 parece estar perdiendo la fuerza que la caracterizó como impulsora de la historiografía económica sobre la región, lo que ha producido que otras instituciones vayan paulatinamente subsanando los vacíos que se generan debido a esta situación y ocupando los espacios en la investigación que se demandan.

\section{La historia económica sobre el Valle del Cauca (aspectos historiográficos)}

\section{Tipo de publicaciones}

A lo largo de las últimas cuatro décadas se han generado una serie de publicaciones que ofrecen un panorama acerca del desenvolvimiento de los estudios sobre la historia económica de la región. Al analizar y dividir -tipificarel conjunto de obras según correspondan a publicaciones en libros, artículos y capítulos de libros, se muestra una idea relativamente exacta del volumen de la producción al presentar de manera indirecta la dedicación de los historiadores al estudio de la economía regional. Aunque la extensión de una investigación en términos de tipo de publicación -o en número de páginas- no puede dar

4 Colmenares realizo sus estudios de postgrado en Francia, cuando la "segunda generación" de los Annales estaban en apogeo, bajo la tutoría de Fernand Braudel. Y en la década de 1970, por circunstancias que no vienen al caso, el marxismo, en su vertiente soviética fundamentalmente, logra gran presencia en sectores de la intelectualidad del país y la región. En síntesis, es el desarrollo de estas dos corrientes y sus investigaciones la que posibilita la consolidación de la historiografía económica sobre la región, lo que en la década de 1970 y 1980 se denomino la historia económica y social. 
cuenta de manera certera sobre la importancia y dedicación -el estado del conocimiento- hacia la historia económica, ni mucho menos de la calidad de los trabajos, si puede arrojar algunas ideas que permiten crear una parte del cuadro que se pretende construir.

Tabla No. 1. Tipo de publicación

\begin{tabular}{|c|c|c|c|c|c|}
\hline Tipo de publicacion & Libros & Artículos & $\begin{array}{c}\text { Balances } \\
\text { Historiográficos } \\
\text { (Artículos) }\end{array}$ & $\begin{array}{c}\text { Capítulos } \\
\text { de libro }\end{array}$ & $\begin{array}{c}\text { Total } \\
\text { publicaciones }\end{array}$ \\
\hline Total & 34 & 53 & 3 & 42 & 132 \\
\hline Porcentaje & $26 \%$ & $40 \%$ & $2 \%$ & $32 \%$ & $100 \%$ \\
\hline
\end{tabular}

Fuente: Obras de la historiografía económica acerca del Valle del Cauca. Siglos XIX-XX.

Como se observa en la tabla No.1, del total de las publicaciones - 132 títulos34 pertenecen a la categoría de libros, el $26 \%$ del total. En la de artículos encontramos 53 publicaciones, el $40 \%$ del total, lo que revela que predomina el tipo de investigaciones monográficas. En orden de importancia se encuentran los capítulos de libros con 42 publicaciones, $32 \%$, lo que refleja una significativa presencia de espacios dedicados a la historiografía económica dentro de obras dedicadas a otros aspectos más generales de historia de la región. La mayoría de los libros donde se encuentran estos capítulos son reconstrucciones generales sobre el Valle del Cauca que, al lado de otras historiografías sectoriales, incluyen un capítulo dedicado al estudio de la historia económica. Esto es un indicio indirecto del nivel de desarrollo de la escritura de la historia económica al constatarse la centralidad que ocupa ésta dentro del conjunto de la investigación histórica. En cuanto a la categoría de balances historiográficos - una categoría que se quiso subrayar- se registran tres publicaciones correspondientes a la forma tipo de publicación artículo. Como se sostuvo, los historiadores poco se han dedicado a la reflexión historiográfica, solo el $2 \%$ del total se ha dedicado a esta tarea, de 132 publicaciones 3 corresponden a balances. Esta es la misma situación para la investigación en general sobre el Valle del Cauca, que cuenta con limitados estados de la cuestión que permitan reflexionar acerca del oficio del historiador y la escritura de la historia regional. 
Aunque el volumen de balances no es alto respecto a las necesidades, ${ }^{5}$ se rescata que existan esfuerzos aislados por dedicarse -así sea de manera ocasionalal examen del oficio de la historia, esfuerzos que constituyen importantes aportes a la investigación de la historia económica. Dichos balances presentan límites como ser recopilaciones de reseńas, no presentar un estado de la cuestión detallado más allá de las principales obras y no ofrecer a modo de sugerencias algunas posibles salidas para el avance. No obstante, son una base para realizar diagnósticos sobre lo que fue y lo que puede ser la rama de los estudios sobre la historia económica regional.

\section{Periodos de publicación. Evolución general}

El ritmo de publicación de las investigaciones sobre la historia económica del Valle del Cauca presenta varias características que permiten establecer algunos indicadores del desarrollo que ha experimentado esta historiografía sectorial. En términos generales, el volumen de publicaciones ha presentado una curva ascendente. No obstante, en los últimos ańos es notorio un desaceleramiento sustancial, en relación a la tendencia de las décadas anteriores. Esto significa que la expansión manifestada en años anteriores por los estudios acerca de la historia económica se encuentra en incertidumbre, aunque pueda esperarse un repunte en los cuatro años restantes de la década del 2000, en cuanto a materia de investigaciones se refiere.

\section{Tabla No. 2. Periodos de publicación}

\begin{tabular}{|c|c|c|c|c|c|c|c|c|c|c|}
\hline 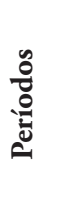 & 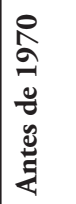 & $\begin{array}{l}\hat{a} \\
\hat{\sigma} \\
\hat{\sigma}\end{array}$ & 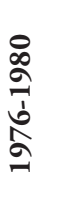 & 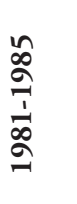 & 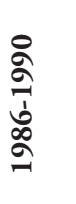 & $\begin{array}{l}\hat{\sigma} \\
\frac{n}{\sigma}\end{array}$ & 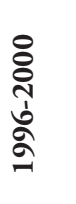 & 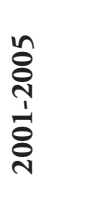 & ઢ્ڤે & 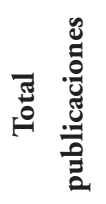 \\
\hline Total & 1 & 3 & 13 & 19 & 22 & 27 & 24 & 21 & 1 & $131^{*}$ \\
\hline$\%$ & $1 \%$ & $2 \%$ & $10 \%$ & $15 \%$ & $17 \%$ & $20 \%$ & $18 \%$ & $16 \%$ & $1 \%$ & $100 \%$ \\
\hline
\end{tabular}

*Falta uno sin fecha de publicación

Fuente: Obras de la historiografía económica acerca del Valle del Cauca. Siglos XIX-XX.

5 Un estado de la cuestión sobre historia empresarial y de empresarios, sobre las investigaciones de historia económica del Valle del Cauca y un balance sobre los estudios de los procesos de poblamiento en el siglo XIX (Mejía, 1999; Ordóñez, 2004; Londoño, 1994). 
En la tabla No. 2 se observa de manera clara esta tendencia. Del periodo de 1991 a 1995 se publicaron 27 obras; de 1996 a 2000 24; y del 2001 al 2005 decayó aún más el volumen de publicación a 21 obras; el año 2006 solo registra una publicación dedicada al estudio de las prácticas de los empresarios en los primeros años del siglo XX. Es poco probable que en lo inmediato se retome un ritmo de investigación y de publicación orientado a reestablecer y superar la tendencia creciente de las décadas anteriores (1970-1980-1990), lo cual, aunado a la no existencia de un núcleo de investigadores y de una línea investigativa clara y consolidada inserta en un campo científico afianzado, permite suponer que en el corto plazo no se vuelva a adquirir un peso y porcentaje significativo dentro de la escritura de la historia. Queda esperar que los esfuerzos individuales, en parte aislados y esporádicos, posibiliten consolidar en los próximos años un repunte en el desarrollo de la investigación sobre historia económica. La tendencia general de los estudios sobre historia económica en Colombia desde la década de 1990 que han sido asumidos por economistas desde perspectivas que van desde el neoinstitucionalismo y los estudios clíometricos, (Meisel, 2005; Kalmanovitz, 2004) no parece tener arraigo fuerte en la región, como quiera que los estudios de los economistas se centran en perspectivas analíticas de coyuntura contemporánea, quedando los estudios de historia económica relegados del análisis.

En la década de 1970 se comienza a desarrollar de manera significativa la investigación sobre historia económica. En esta década se publicaron 16 obras, el $12 \%$ del promedio total de publicaciones, en franco contraste con las décadas anteriores donde figura un solo estudio. Este fenómeno solo es comprensible como resultado de la profesionalización de la disciplina histórica, el debilitamiento de la historiografía académica tradicional y el arribo de algunas tendencias teóricas, Anales y el marxismo, que privilegiaban el estudio de la esfera de lo económico en la escritura de la historia, con lo cual contribuyeron a la conformación y consolidación de la investigación en este área. El crecimiento del número de publicaciones sobre historia económica en esta década indica en el espectro de los estudios históricos sobre la región un cambio significativo en las orientaciones temáticas, epistemológicas y teóricas ${ }^{6}$ que guiaban la producción de conocimiento, cambio significativo que se constituirá en la base de la conformación de un espacio dedicado al estudio de la economía sobre el Valle.

En la década de 1980 se observa una tendencia creciente, al doblarse el número de publicaciones respecto a la década inmediatamente anterior. Con

6 Cambio de una historiografía producida por políticos o empresarios de la región como Hernando Caicedo y Phanor Eder hacia una historiografía elaborada por historiadores profesionales, y cambio de los centros de investigación como la Academia de Historia hacia centros de formación de la moderna disciplina histórica en instituciones universitarias. 
41 títulos, un porcentaje del $31 \%$, la producción en esta década alcanza uno de sus puntos más álgidos, situación que favorece la consolidación de los estudios sobre la historia económica. En el contexto general de desarrollo de la disciplina histórica en el país, se advierte que este panorama coincide con el momento más general de consolidación de la "historia económico-social" en el país.

Cuantitativamente, la década de 1990 representa el punto cúspide del número de publicaciones participando de un 39\% del total de obras seleccionadas. Con 51 publicaciones, el decenio de 1990 presenta un buen ritmo de publicaciones. Sin embargo, en la década de 1980 la escritura de la historia económica alcanza su punto más álgido en términos cualitativos, a pesar que en la década de 1990 el número de publicaciones sea más alto. Esto tiene que ver con las publicaciones escogidas para el decenio de 1990, donde por los criterios de selección y la definición de historiografía económica adoptados se incluyeron algunas obras conmemorativas sobre algunas empresas de la región, obras que en términos rigurosos no presentan ni fueron escritas con fines académicos ni constituyen obras con rigor científico, aunque realizan aportes en cuanto al conocimiento descriptivo.

Esta situación se torna confusa debido a que el análisis aquí realizado es cuantitativo y no cualitativo. Por eso, a nivel cuantitativo, la década de 1990 es la más importante para la publicación, al registrar el mayor número y porcentaje de estudios por décadas; no obstante, y esto esta abierto a una investigación que examine contenidos y problemas, en términos de desarrollo cualitativo (de grado de complejización, explicación y comprensión), la década de 1980 constituye el periodo donde se dieron los mayores avances en cuanto al conocimiento histórico sobre la economía regional. Un análisis detallado de hipótesis, fuentes, problemas, perspectivas teóricas confirmaría -o no confirmaría- esta aseveración.

Con esta idea se pretende resaltar una leve tendencia hacia el abandono del estudio disciplinar, científico, de la historia económica de la región, su puesta a la deriva del estudio a instituciones, empresas privadas o historiadores aficionados que no cuentan con la formación adecuada para la construcción de un conocimiento estándar al nivel de los mejores trabajos e investigaciones. La tendencia observada desde la década de 1970 y 1980 de conformación y consolidación de una historiografía económica realizada siguiendo parámetros científicos de la moderna disciplina histórica y por profesionales del oficio de la historia y demás Ciencias Sociales, parece ceder ante el surgimiento de un cúmulo de publicaciones -particularmente sobre historia empresarial- elaborados por empresas privadas, que constituyen estudios laudatorios y poco reflexivos con fines principalmente conmemorativos y no académicos, y por autores, ya sea 
institucionales o no pertenecientes al campo científico de los estudios sobre la historia económica de la región.

En este sentido, la década de 1990 constituye el punto de inflexión de los estudios históricos sobre la economía de la región, al presentar un retroceso frente a los avances logrados en el decenio de 1980; inflexión que parece, en lo que va del año 2007, pronunciarse de manera tenue y no reversible, dadas las perspectivas y posibilidades que se observan en la actualidad. No hay indicios claros y consolidados -en algunos casos ni siquiera en proyección-, de esfuerzos para superar esta situación. El panorama en los programas de investigación de los departamentos de economía, sociología o historia no dan muestras de esto -al menos en lo que se refiere a las universidades locales-, aunque no faltan los esfuerzos aislados que pretenden revertir este proceso. Los economistas no parecen interesarse en la historia económica, sumergiéndose en cambio en estudios de coyuntura regionales de no mas de una década y espacios temporales circunscritos a las décadas de 1980, 1990 y lo que va corrido del 2000. Por su parte, los historiadores -al revisar las publicaciones y tesis de los últimos diez años- parecen desinteresarse de este campo de los estudios históricos, embarcándose en el desarrollo de otras historiografías sectoriales y otras temáticas a la luz y el eco de los intensos debates sobre la "crisis" de la historia y las nuevas perspectivas de escritura de la historia producida por los cambios de paradigmas en las Ciencias Sociales. Los sociólogos por el momento no parecen dar signos de emprender una mirada hacia los problemas de la historia económica.

Con 22 publicaciones, la década del 2000 registra el 17 por ciento restante del total de publicaciones. Esta cifra es indicativa del momento por el que transcurre la investigación de la historia económica, porque -al tener en cuenta que el periodo va del 2001 al 2006- evidencia la continuación de la tendencia de caída de la aceleración del ritmo de publicación, ${ }^{7}$ máxime al señalar que para este periodo también aplican las aclaraciones realizadas respecto a la década de 1990 que destacaban un porcentaje de publicaciones que eran de autoría de empresas o autores institucionales y no de profesionales del oficio de la historiografía económica. ${ }^{8}$

7 El numero de publicaciones de lo que va de la década del 2000 -22- no alcanza ni siquiera la mitad del decenio de 1990 -51-, y apenas sobrepasa - por una publicación-a la de 1980, lo cual es significativo teniendo en cuenta que debería haber sobrepasado dicha mitad dado que ya se ha cumplido la mitad del transcurso de la década del 2000.

8 Aunque puede dudarse de la existencia de un grupo de profesionales especializado en el estudio de la historia económica de la región -como por ejemplo sí se encuentra para otras regiones de América Latina, Estado Unidos o Europa-, la tendencia observable en la década de 1970, 1980 y parte de 1990 son las investigaciones de la historiografía económica producidas por profesionales de Clío, la economía o la sociología. Véase acápite de autores, disciplina autores y nacionalidad. 
Las razones y explicaciones de la crisis o del desaceleramiento del ritmo de publicación pueden ser varias, pero se sostiene que se debe a una serie de circunstancias externas ${ }^{9}$-tanto a nivel nacional como internacional- como la perplejidad y repercusiones que ha producido el debate sobre la "crisis de las Ciencias Sociales" y la Historia, sumado al auge de nuevos enfoques y perspectivas que han captado el centro de atención en materia de investigación y objetos de estudio. Estos nuevos enfoques han llevado a los historiadores y demás científicos sociales a alejarse de la investigación histórica de la economía y a sentirse animados a explorar problemas como los de la nueva historia cultural, política, entre otras, que comienzan a tener presencia en el seno de la disciplina histórica regional y nacional; y de manera fundamental, a que el campo de los estudios históricos de la economía del Valle del Cauca es un campo aún en proceso de consolidación, con un débil y corto afianzamiento que no ha logrado extenderse y profundizarse, lo que permitió que el debate exterior y las nuevas orientaciones paradigmáticas afectaran de manera profunda al desarrollo de la historiografía económica.

En conclusión, el ritmo de publicaciones presenta una tendencia en sus primeras décadas fuertemente ascendente y en sus últimos años tendiente al estancamiento y retroceso en materia de número de publicaciones.

\section{Los autores de la historiografía económica sobre la región}

Alonso Valencia Llano indica, en un balance sobre el apoyo institucional al desarrollo de la historiografía regional (2001), que la investigación profesional se inició en el departamento de Historia de la Universidad del Valle gracias a la influencia de autores extranjeros; es el caso de la presencia de historiadores norteamericanos que llegaron hacia finales de la década de 1960 y 1970, cuando León Helguera, Jorge Castellanos o William Lofstrom le daban a sus investigaciones un carácter regional. Esto se vio complementado por la presencia de historiadores nacionales de la categoría de German Colmenares y Jorge Orlando Melo cuya influencia en la formación de historiadores regionales es innegable, como resultado de la creación del departamento de Historia, de Economía, Sociología y la Licenciatura en Ciencias Sociales de la Universidad del Valle (interesándose algunos estudiantes y profesores por la historia económica regional).

Como resultado de este proceso -y otros factores no relacionados aquí-, a lo largo del desarrollo de esta área de estudios se ha conformado de manera tímida y tenue un campo historiográfico donde convergen diversas disciplinas, diferentes

9 A un ambiente intelectual donde las clásicas temáticas y problemas de la historiografía y las ciencias sociales son sustituidas por nuevos enfoques que renuevan y cambian la investigación histórica. 
orientaciones teórico-metodológicas y diversos autores que se han dedicado en alguna medida y en algunos momentos de su profesión al conocimiento histórico de la economía del Valle del Cauca. La conformación y consolidación de un grupo permanente de científicos dedicados a la investigación, discusión y presentación de los resultados de sus estudios es fundamental para el desarrollo de una historiografía sectorial, pues asegura la continuidad del avance del conocimiento de determinadas temáticas, líneas y problemas de investigación. Por eso, un indicativo del estado de desarrollo de la escritura de la historia lo constituye el número de autores consagrados a su cultivo, ${ }^{10}$ permitiendo observar y trazar la posible existencia o configuración de un campo científico sobre la historia económica de la región (Bourdieu, 1999: 9).

\section{Tabla No. 3. Autores}

\begin{tabular}{|l|c|c|c|c|c|}
\hline $\begin{array}{l}\text { Numero de } \\
\text { autores por } \\
\text { publicación }\end{array}$ & $\mathbf{1}$ autor & $\mathbf{2}$ autores & $\begin{array}{c}\text { Más de dos } \\
\text { autores }\end{array}$ & $\begin{array}{c}\text { Autores } \\
\text { insttucionales }\end{array}$ & $\begin{array}{c}\text { Total } \\
\text { autores }\end{array}$ \\
\hline Total & 50 & 9 & 4 & 4 & 67 \\
\hline Porcentaje & $75 \%$ & $13 \%$ & $6 \%$ & $6 \%$ & $100 \%$ \\
\hline
\end{tabular}

Fuente: Obras de la historiografía económica acerca del Valle del Cauca. Siglos XIXXX.

Con un total de 132 publicaciones, la historiografía económica sobre el Valle cuenta con un número aproximado de 67 autores (Tabla No. 3), cifra importante y significativa que podría ser indicativa de dos situaciones: una, los estudios sobre la economía regional han logrado captar un número altamente considerable de investigadores dedicados a su desarrollo, aspecto positivo al constatarse en su seno una cantidad y diversidad de posiciones favorables para el avance en el conocimiento y la discusión; o dos, tal cantidad de autores es expresión de una situación característica de la historiografía económica al presentar un campo inexistente o débilmente consolidado, sin contar con una base mínima de investigadores especializados en su cultivo y desarrollo. En esto

10 Aunque resulta más exacto examinar cuantos de esos autores se dedican de manera recurrente, reiterativa o especializada -ya que algunos solo lo hacen una vez o de manera excepcional-, el número de autores puede dar alguna idea aproximativa de la atención con que cuenta por parte de los historiadores o demás científicos sociales la historiografía económica sobre el Valle del Cauca. 
subyace la historia económica como objeto de investigación ocasional de los científicos sociales. Sin importar la valoración positiva o negativa de estas dos posibilidades, se ha contado con las bases para la conformación de un campo científico consolidado impulsor de la creación de líneas de investigación que permitan avanzar en el conocimiento. La pregunta a resolver es por qué razón este campo no se ha afianzado.

Como se observa, de los 67 autores encontrados el 75\% corresponde a la categoría de 1 autor por publicación, mientras que en la de 2 autores por publicación figuran 9-13\%-, lo que revela un avance en la elaboración de investigaciones que involucran a varios investigadores, al favorecer y generar el desarrollo de estudios "interdisciplinarios", tendencia que se reafirma con la categoría de más de 2 autores, 4 publicaciones - el 6\% del total- donde han intervenido varios autores en el desarrollo de las investigaciones. El número de autores institucionales, 4 -el 6\%-, aunque no represente un número alto respecto a las otras categorías, es significativo ya que en los últimos años esta tendencia ha aumentado levemente, al constituirse un tipo de escritura de la historia realizada por autores institucionales -sobre todo empresas- que realizan sus investigaciones por encargos.

En general, ha sido la historia profesional la que ha impulsado el desarrollo de la historiografía económica, aunque en los últimos años han crecido los estudios realizados por autores institucionales o contratados por empresas u otras instituciones. Lo anterior evidencia el creciente interés de las instituciones privadas por asumir el estudio de algunos -especialmente de empresas o instituciones económicas-aspectos de la economía de la región, dada la situación actual por la que transcurre ${ }^{11}$ y el debilitamiento de la investigación que no ha logrado abordar y dar respuesta satisfactoria a importantes problemas de la situación económica - política y social- del Valle del Cauca, a finales del siglo $\mathrm{XX}$ y comienzos del XXI, que tienen que ver directamente con su desarrollo histórico económico desde el siglo XIX.

En el ámbito institucional, destaca el apoyo que se ha recibido por parte de instituciones ligadas a la gobernación del Valle con su Colección de Autores Vallecaucanos, y del Fondo Editorial de la Facultad de Humanidades de la Universidad del Valle, las cuales generan la cuota más importante en cuanto a la publicación de trabajos de investigación histórica sobre la economía regional. En este aspecto, una de las entidades más importantes en el desarrollo de la historiografía regional y la investigación en historia económica en particular,

11 Es conocido el debate surgido a propósito de la diagnosticada crisis (política, económica, social, cultural y "cívica") del Valle del Cauca desde la década de 1990. El recurso a la historia ha sido recurrente, al buscar en el pasado una supuesta cultura cívica-ciudadana la cual se ha perdido en la actualidad, lo que ha causado la fractura social que se experimente. 
lo constituye desde su inicio el departamento de Historia de la Universidad del Valle en la formación de historiadores profesionales, ${ }^{12}$ debido a que gran parte de los historiadores que conforman o conformaron el campo de la historiografía económica han recibido su formación inicial en esta universidad. Desde aquí se ha estimulado la investigación -limitada, aunque significativa- y la publicación de algunas de las obras más importantes, gracias a la existencia de un ente institucional en el cual se forman investigadores y docentes, se realizan y producen investigaciones, y se divulgan y socializan los resultados.

\section{Disciplina de los autores}

En esta sección se construye una idea general sobre las aproximaciones disciplinares en el desarrollo de la escritura de la historia económica acerca del Valle del Cauca durante los siglos XIX y XX. A pesar de la poca exactitud de los datos elaborados, estos pueden dar una idea que permita establecer qué disciplinas confluyen y su porcentaje en el nivel de participación. A su vez posibilitan anotar el grado de diversidad de miradas disciplinares que ha logrado la historia económica regional y señalar algunos aspectos que puedan ayudar a la superación de la "crisis" o el "estancamiento" evidenciado a lo largo de estas líneas. La característica principal es la alta presencia de historiadores, si bien existe una importante cuota de otras disciplinas como la Sociología, las Ciencias Sociales o la Economía en el campo historiográfico (Tabla No. 4).

\section{Tabla No. 4. Disciplina de autores}

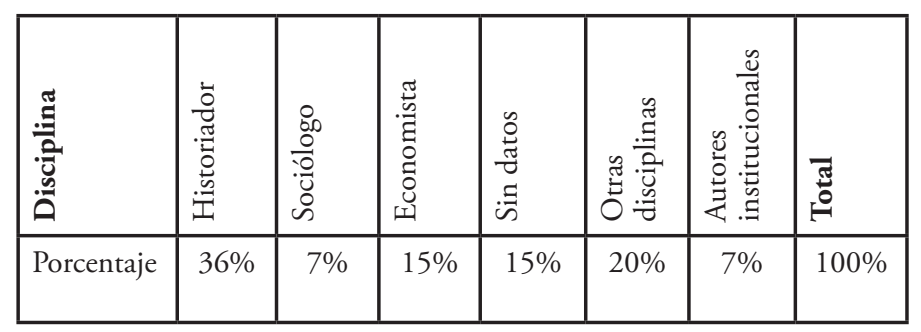

Fuente: Obras de la historiografía económica acerca del Valle del Cauca. Siglos XIX-XX.

12 Esta situación tal vez pueda cambiar en décadas siguientes debido a la apertura de las universidades privadas de la región a las carreras enfocadas en las ciencias sociales -en el ámbito de la formación profesional, la investigación y la divulgación-. 
La composición disciplinar del campo de la historiografía económica acerca del Valle del Cauca se encuentra compuesta, en su mayoría, por historiadores, quienes son los que más se han dedicado a su cultivo con un porcentaje del $36 \%$. La mayoría de estos autores son historiadores profesionales, encontrándose algunos historiadores "aficionados", que recibieron su formación inicial de pregrado o postgrado en el Departamento de Historia de la Universidad del Valle, centro de formación de historiadores económicos en la región. ${ }^{13}$ En cuanto a las temáticas y problemas objeto de estudio se refiere, los historiadores son los que más variedad han desarrollado en este aspecto, con una leve tendencia a la concentración en el siglo XIX, aunque existe un buen número de historiadores dedicados también al siglo XX -sobre todo a inicios de éste-. Un futuro reimpulso de los estudios históricos sobre la economía regional, estará en gran medida determinado por el esfuerzo y constancia en la participación que los historiadores estén dispuestos a proporcionar mediante la investigación y el debate sobre este tipo de estudios.

En contraste, los economistas se muestran reticentes hacia la investigación en historia económica, al contar con solo una participación del 15\%. Tal vez las barreras disciplinares o teóricas han generado esta situación en la que los economistas poco se interesan no solo por el análisis de la economía en tiempos o fechas que se distancian considerablemente de ellos -por ejemplo el siglo XIX o comienzos del siglo XX-sino también en estudiar la economía como un aspecto, proceso o fenómeno que ocurre en el espacio y en el tiempo. Sus investigaciones estudian, en términos de tiempos o periodos históricos, lapsos de una década, con énfasis en los análisis de corta duración, estático estructurales, con ausencia de las ventajas de un análisis dinámico de larga o mediana duración. Esto ha llevado a que los pocos estudios realizados por economistas se hayan realizado desde la perspectiva de los análisis de coyuntura sobre diversos aspectos de la historia económica regional, como por ejemplo sobre el sector cafetero, ${ }^{14}$ con análisis tan solo desde la década de 1970 y sin intentar reconstruir un periodo más lejano en el tiempo. No obstante, es necesario resaltar que algunos economistas han escapado a esta característica y han logrado importantes estudios sobre la evolución de la demografía durante todo el siglo XX, el desarrollo económico, las industrias y empresarios pioneros y la historia del desarrollo urbano de Cali. ${ }^{15}$

13 Esta situación no parece tener continuidad hacia unos próximos ańos, dada la poca atención -y el leve declive o estancamiento- que profesan los estudiantes en trabajo de grado y los historiadores egresados de la universidad del Valle hacia las temáticas y problemas de índole económico de la región.

14 Es necesario reconocer los aportes que han brindado al conocimiento sobre esta temática y problemática tan importante en la historia económica regional, debido a que son los únicos dentro de las diferentes disciplinas presentes en el campo de la historiografía económica que se han atrevido al estudio de dicho sector productivo.

15 Las fechas de publicación de las obras economistas son las décadas de 1980 y 1990. 
En orden de importancia continúan los sociólogos, quienes con una participación del 7\% inscriben su presencia dentro de las investigaciones históricoeconómicas. Esta disciplina tiene una presencia, aunque poco importante en términos de cantidad o porcentaje de autores, con importantes trabajos sobre la formación de la burguesía azucarera, la formación del campesinado y la innovación y la cultura de las organizaciones y la historia empresarial de la región. En la categoría de Otros incluimos a las demás disciplinas presentes que van desde profesiones tan cercanas a la historia, la Economía o la Sociología como las Ciencias Sociales, el Derecho o la Geografía -que tratan temas del desarrollo de la economía, la caña de azúcar, las transformaciones económicas y culturales, hasta disciplinas como la Arquitectura, ${ }^{16}$ las ingenierías o la Antropología-. ${ }^{17}$ Esta apertura de disciplinas en apariencia tan lejanas y dispares hacia el objeto de la historia económica contribuirá mucho en el afianzamiento, renovación y desarrollo de los estudios sobre la economía regional.

\section{Nacionalidad de los autores}

En un análisis de la historiografía norteamericana sobre Colombia, Jesús Antonio Bejarano (1994) destaca la importante contribución -cerca de más de 250 títulos- de los investigadores extranjeros al conocimiento de la historia económica del país en diferentes áreas y temáticas. En el área de los estudios regionales, Antioquia, constataba, ha recibido la mayor parte de la atención, dentro del gran número de investigaciones dedicadas a esta área por parte de los autores extranjeros. En el caso del Valle, como se observa en la tabla No. 5, esta no parece ser la misma situación, debido a la débil presencia de autores extranjeros. Del total de autores -67- de la historiografía económica, solo 5 -el 7\%- son investigadores de otros países (Estados Unidos, Chile, Alemania, Australia); la mayoría -62, el 93\%- son autores de origen nacional. Esto es indicador de la escasa atención que ha obtenido la historia económica del Valle del Cauca por parte de los investigadores extranjeros, dada la centralidad que ha gozado la región antioqueña -o Cundinamarca y Santander- en el conjunto del país.

16 Gracias a un arquitecto de la Universidad del Valle contamos con un buen trabajo sobre las industrias en Cali durante las primeras cinco décadas del siglo XX, donde se relacionan aspectos arquitectónicos de estas, la ciudad y las técnicas empleadas en estas.

17 Entre las temáticas desarrolladas encontramos el estudio de los negociantes en el siglo XIX y parte del $\mathrm{XX}$, los primeros vapores en el Cauca, un estudio sobre la historia económica de Candelaria y Restrepo, las transformaciones paisajísticas en la zona plana del Valle y las transformaciones laborales en el campo vallecaucano, sobre la crisis y destrucción de la economía colonial y acerca de la destrucción del campesinado y la formación del proletariado agrícola. 
Tabla No. 5. Nacionalidad de autores

\begin{tabular}{|l|c|c|c|}
\hline Nacionalidad & Nacionales & Extranjeros & Total Autores \\
\hline Total & 62 & 5 & 67 \\
\hline Porcentaje & $93 \%$ & $7 \%$ & $100 \%$ \\
\hline
\end{tabular}

Fuente: Obras de la historiografía económica acerca del Valle del Cauca. Siglos XIX-XX.

Los investigadores extranjeros se han dedicado al análisis de temáticas y problemas como la formación de la burguesía azucarera durante las décadas de 1930 y 1940, la estructura agraria, el crédito y la economía entre los ańos de 1851 y 1880, el desarrollo industrial en la región, la economía y el espacio del Valle del Cauca entre 1850 a 1950 y el desarrollo económico de Buenaventura, la historia del campesinado y su descomposición, las economías campesinas y el desarrollo de la agricultura capitalista. Se aborda en mayor proporción el siglo $\mathrm{XX}$, aunque un trabajo conjunto estudia los dos siglos. Predomina el tipo de publicación bajo la forma artículo o capítulo de libro, y se cuenta con tres libros importantes realizados por estos autores extranjeros.

En cuanto a los autores nacionales, aunque no se demuestra de forma explicita, en su gran mayoría pertenecen o ejercen su profesión en la región, destacándose la poca atención de parte de investigadores de otras regiones, característica apenas natural dado el carácter localista y regionalista que caracteriza el campo historiográfico regional y nacional.

\section{La historia económica del Valle del Cauca: temas, espacios y tiempos Temáticas abordadas}

El estudio de la historia económica de la región presenta una limitada diversidad temática, al presentarse una pronunciada concentración alrededor de tres o cuatro temas que se han erigido como privilegiados de la investigación histórica sobre el Valle del Cauca durante los siglos XIX y XX. De las categorías tenidas en cuenta -16-, solo tres de ellas concentran el 53\% del total de la producción, mientras que las restantes -13-oscilan con un porcentaje alrededor del 2, 4 o 5\%. Esto evidencia una concentración en las investigaciones que tienen como objeto la historia empresarial, los análisis generales y la historia local, un desarrollo desigual y limitado referente a los temas y aspectos de la historia económica de la región, lo que ha configurado un conocimiento parcializado -pocos estudios sobre algunas problemas- y centralizado alrededor de unos 
pocos temas sobre la economía de la región. Este panorama se presenta más crítico cuando se comprueba la inexistencia de trabajos e investigaciones sobre algunos procesos que han sido invisibilizados por el campo de la historiografía económica sobre la región.

Tabla No. 6. Temáticas

\begin{tabular}{|c|c|c|c|c|c|c|c|c|c|c|c|c|c|c|c|c|c|}
\hline 胥 & 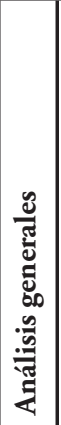 & 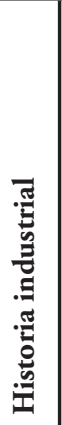 & 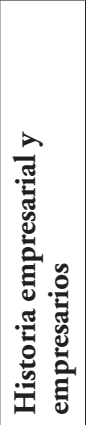 & 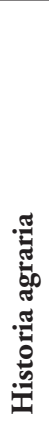 & 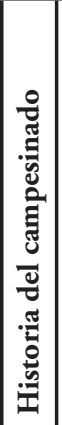 & 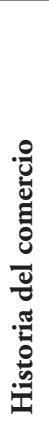 & 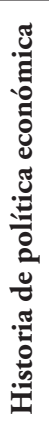 & 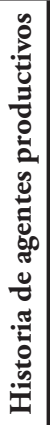 & 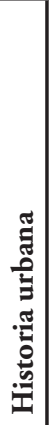 & 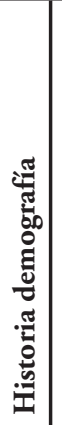 & 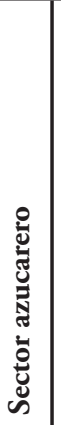 & 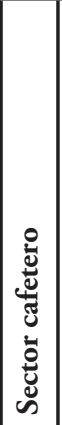 & 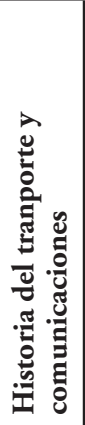 & 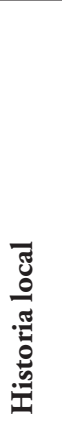 & 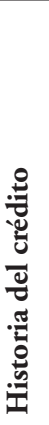 & 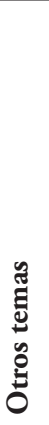 & 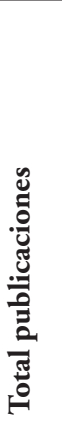 \\
\hline Total & 20 & 10 & 30 & 10 & 9 & 1 & 4 & 5 & 7 & 2 & 7 & 3 & 3 & 17 & 2 & 2 & 132 \\
\hline$\%$ & 14 & 8 & 22 & 8 & 7 & 1 & 3 & 4 & 5 & 2 & 5 & 2 & 2 & 13 & 2 & 2 & 100 \\
\hline
\end{tabular}

Fuente: Obras de la historiografía económica acerca del Valle del Cauca. Siglos XIX-XX.

Las categorías que concentran el mayor número de publicaciones son, en primer lugar, la historia empresarial y de empresarios, con un numero de 30 publicaciones $-22 \%$-, en segundo lugar los análisis generales -donde se tratan diversos aspectos- con 20 publicaciones $-14 \%-y$, en tercer lugar, las historias locales -sobre municipios o pueblos del Valle del Cauca-, con un total de 17 publicaciones -13\%- (Tabla No. 6). Como se observa, en realidad solo la historia empresarial y de empresarios ha conseguido un desarrollo considerable en el conjunto de los estudios sobre la economía de la región, debido a que la segunda categoría en importancia -los análisis generales- contiene varias temáticas que intentan brindar una visión de conjunto, y la tercera -la historia local- incluye diversos temas enmarcadas en espacios locales. Para la historia empresarial y de empresarios existen trabajos que realizan la biografía de varios empresarios, historias biográficas de empresas, estudios sobre las practicas empresariales, sobre historia de la cultura y de la organización empresarial, estudios de las industrias y empresarios "pioneros" en Cali, y sobre los empresarios y negociantes del siglo XIX y principios del XX, además de un balance de la historiografía empresarial sobre el Valle del Cauca. 
El peso del número de publicaciones enmarcadas en los análisis generales -20 títulos, el $16 \%$ - evidencia un esfuerzo por la elaboración de análisis amplios que integren heterogéneos problemas y aspectos que permitan reconstruir cuadros generales de la historia económica regional. La mayoría de trabajos investigan aspectos genérales bajo el rotulo de "desarrollo económico", o intentan brindar una visión panorámica de la "economía del Valle del Cauca", al tomar como temporalidad amplios o cortos periodos del siglo XIX y el XX. Estudios, desde una perspectiva general, sobre el impacto del narcotráfico en la economía vallecaucana en la década de 1980, sobre el desarrollo regional a través del papel de la CVC, sobre la configuración moderna de la región y una publicación sobre las ciudades intermedias como polos de crecimiento regional. También una investigación acerca de los determinantes de comportamiento de corto plazo de la economía vallecaucana -década de los ochenta, siglo XX-, y un balance de la historiografía económica sobre la región durante el siglo XIX.

En la categoría historia local ${ }^{18}$-que representa el 13\% del total, 17 publicaciones- figura también un esfuerzo y un avance en el conocimiento de la historia económica del Valle del Cauca, al ocupar, en el conjunto de las investigaciones, los análisis locales un renglón y atención importante que constituye un avance en el conocimiento de dinámicas particulares que enriquecen el panorama regional general. No obstante, se confirma una centralización de la investigación alrededor del municipio de Cali -más de la mitad de las 17 publicaciones corresponden a esta ciudad-, con lo que se deja de lado importantes y fundamentales localidades en el estudio, comprensión y explicación de la historia económica de la región. Tal es el caso de zonas del norte del Valle donde se ha desarrollado una importante industria vinícola y de algunas localidades donde se concentró la actividad cafetera de la región, las cuales se mantienen débilmente estudiadas -o casi inexploradas-. Los estudios tratan sobre el desarrollo económico en general y las transformaciones económicas de los municipios -Restrepo, Bolívar, Bugalagrande, Cerrito, Candelaria, Buenaventura-. Los centrados alrededor de la ciudad de Cali enfatizan aspectos como la recesión y el cambio de régimen político en los años 30 del siglo XX, el desarrollo económico y los procesos de modernización e industrialización-Cali y Yumbo-. Sobresalen vacíos en el estudio de otros municipios importantes en la dinámica económica regional -como Tulúa y algunas ciudades del norte del Valle-, lo que hace necesario empezar un proceso comparativo entre las diferentes localidades, porque una de las características de la historiografía económica es presentar una visión monolítica, centrada alrededor de pocos municipios como

18 Los trabajos de esta categoría presentan análisis generales sobre la historia económica de algunos municipios. Cuando encontramos trabajos enmarcados en espacios locales pero que tenían como objeto una temática concreta, estos se incluyeron en la temática correspondiente y no en la de historia local. 
Cali y Yumbo y de algunos sectores productivos como el azucarero -el Ingenio Manuelita-, del desenvolvimiento económico regional.

Otras temáticas que tienen presencia considerable son la historia industrial y la historia agraria, cada una con un total de 10 publicaciones y con un porcentaje de $8 \%$ respectivamente. Estos temas, aunque tienen una presencia relativamente consistente en el seno en los estudios históricos sobre la región, se encuentran aún en un estado incipiente de desarrollo, dado que los problemas de la industrialización y de la estructura agraria constituyen uno de los aspectos y problemas por investigar a la hora de la comprensión y explicación de la estructura económica y su desenvolvimiento durante los siglos XIX y XX. En el tema de la historia industrial, existen trabajos sobre la industrialización de la producción cañera -el ingenio Manuelita-, sobre los comienzos y el desarrollo de la industrialización en la región, el desarrollo de la agroindustria -en la ciudad de Buga-, las relaciones entre arquitectura, industria y ciudad en el Valle, y dos estudios particulares sobre los procesos de industrialización en las ciudades de Palmira y Yumbo. En la historia agraria contamos con un trabajo sobre economía campesina y desarrollo de la agricultura capitalista, acerca de la tenencia de la tierra -para el siglo XX-, haciendas y estructura agraria en la región -siglo XIXy sobre penetración de las relaciones asalariadas en el campo. Aún es mucho lo que falta por estudiar sobre el agro y el campo vallecaucano -sobre todo para el siglo XX y algunos periodos del XIX-.

De igual manera problemas tan importantes como la historia del campesinado, que cuenta con 9 publicaciones -el 7\% del total-, ha logrado un considerable grado de desarrollo, al contar con algunos estudios que brindan una visión general de algunos aspectos fundamentales del funcionamiento de las sociedades campesinas. La mayoría de trabajos reconstruyen los procesos de formación de las diversas comunidades campesinas a lo largo de las orillas del Río Cauca, comunidades que se convirtieron en la base de la fundación de muchos de los actuales pueblos de la región. Se encuentran investigaciones sobre la situación de la pequeña posesión campesina, las formas de insurgencia que se generaron en el proceso de consolidación del campesinado y la elaboración de un balance historiográfico sobre el poblamiento en el Valle; estudios que se concentran a finales del siglo XVIII y en el siglo XIX. En cambio, se adolece de estudios sobre la evolución del campesinado en el siglo XX, acerca de sus formas y organización productiva, sus formas de producción y comercialización, sobre los procesos de proletarización ${ }^{19} \mathrm{y}$ expropiación de tierras para la posterior formación del gran latifundio azucarero en la zona plana del Valle del Cauca. 
La historia urbana, que figura con 7 publicaciones $-5 \%$ - contiene trabajos que ofrecen una visión sobre algunos aspectos fundamentales del desarrollo urbano, de los servicios públicos y de la evolución y desarrollo de las tierras públicas o ejidos. Dentro de los estudios sobre sectores o renglones productivos abordados por la historiografía económica, el sector azucarero cuenta con el mayor número de publicaciones y los mayores desarrollos obtenidos desde el punto de vista del conocimiento del proceso de conformación de la producción azucarera. El desarrollo de la industria azucarera, al erigirse como el sector más importante en el conjunto del sector externo de la economía regional, ha hecho que los investigadores privilegien este sector dedicándole especial atención, lo cual ha llevado a una invisibilidad de otros sectores que han tenido una importancia fundamental -más que el mismo sector azucarero para la comprensión de determinados problemas y procesos- en el desenvolvimiento de la historia económica del Valle del Cauca. ${ }^{20}$ Sin embargo, los estudios sobre el sector azucarero aún distan de configurarse en una temática consolidada. ${ }^{21}$ Los aspectos tratados corresponden a estudios relacionados con una visión general de la cańa de azúcar, las relaciones laborales en la transformación de la hacienda vallecaucana en ingenio azucarero, sobre la formación de la burguesía azucarera y sobre el papel de los empresarios en la formación del sector azucarero, además de un estudio referente a competencia y cambio técnico en el sector azucarero en la década de 1980.

En cuanto a la historia de los agentes productivos, ${ }^{22}$ como se observa, se cuenta con $4 \%$ del total de publicaciones. Cinco títulos donde se analizan problemas como la formación de las clases y grupos sociales, la fuerza de trabajo en el Cauca Grande en el periodo de la independencia y un trabajo sobre la estructura social y el mercado de trabajo en una zona cafetera del norte del Valle del Cauca. Estudios centrados en el siglo XIX, lo que significa que se adolece de un significativo vacío en el conocimiento sobre los aspectos y problemas de la historia de los agentes productivos que impide trazar la evolución y los cambios sucedidos en el transito del siglo XIX al XX y durante éste en la composición de la fuerza de trabajo, la creación de grupos sociales sujetos a relaciones asalariadas y modernos sectores de población participantes en la producción como clases trabajadoras.

Los estudios sobre política económica han tenido una presencia, aunque de resaltar, tenue, con dos autores -ambos historiadores-que se han dedicado a esta temática al tratar aspectos como los proyectos económicos de los regeneradores

20 Tal es el caso particular del sector cafetero, el cual -como mostraremos más adelante-adolece de estudios que resalten su importancia en el desarrollo económico del departamento.

217 publicaciones que representan alrededor de 5 investigaciones, algunas de las cuales presentan generales y poco documentados análisis sobre la cana de azúcar.

22 No incluye a los empresarios y comerciantes que son agrupados en una temática aparte. 
durante el periodo de 1875 a 1890, las prácticas e imágenes de modernización y modernidad en la política en el Valle del Cauca y un breve capítulo de libro dedicado al estudio del proyecto económico y el espacio político de la elite dirigente regional, para un total de 4 publicaciones que constituyen el 3\% del total de publicaciones. Estos trabajos representan importantes aportes, pues reconstruyen la forma en que sectores de empresarios y políticos ayudaron a impulsar mediante políticas públicas el desarrollo económico y la modernización de la región.

El otro sector productivo presente - de manera igualmente leve- en el conjunto de los estudios es el sector cafetero, el cual ha recibido escasa atención por parte de los investigadores. Posee un número de 3 publicaciones, las cuales representan apenas un $2 \%$ del total de investigaciones publicadas. Dentro de los aspectos emprendidos en estas publicaciones se halla un estudio acerca de la modernización de la producción cafetera desde la perspectiva de análisis de coyuntura y dos estudios de carácter general donde se intenta insertar la actividad cafetera en el proceso de desarrollo económico regional. Es importante señalar que entre todos estos estudios no figuran historiadores de profesión, sino que todos han sido elaborados por autores que pertenecen a otras disciplinas de las Ciencias Sociales. ${ }^{23}$ La historiografía económica se caracteriza por la escasa investigación de los diferentes sectores y renglones productivos presentes en la región, que no se reducen al sector azucarero ni el cafetero, sino que incluyen a otros sectores como el ganadero, el vinícola, entre otros, que si bien no tienen ni han jugado el mismo papel en términos de peso en el desenvolvimiento económico de la región, han jugado papeles subsidiarios y coayudantes en el desarrollo económico que la han llevado a ocupar en el conjunto del país una de las regiones centrales en cuanto a economía se refiere.

La historia de los transportes y las comunicaciones presenta el mismo panorama. Con 3 publicaciones, un bajo $2 \%$ del total de obras, se caracteriza por un escaso desarrollo en términos cuantitativos, ocupándose de aspectos como la navegación a vapor por el Río Cauca y del papel de empresarios en ésta como C.H. Simmonds y sobre los primeros vapores en el Alto Cauca, estudios temporalmente enmarcados en el siglo XIX y limitados al terreno de la navegación fluvial a vapor. De acuerdo a este panorama, se desconocen aspectos y problemas centrales relativos a las formas de comunicación (carreteras, ferrocarriles, tranvías, caminos, etc.) que se crearon y establecieron, para ayudar a formar e interconectar los pequeños mercados locales, lo que a su vez permitió la consolidación de un mercado regional inserto en el mercado tanto nacional

23 El primer trabajo señalado sobre la modernización de la producción cafetera es de autoría de un sociólogo y los dos sobre el papel del café en el desarrollo económico vallecaucano han sido elaborados por un economista, ambos autores pertenecientes a la Facultad de Ciencias Sociales y Económicas de la Universidad del Valle. 
(con los otros mercados regionales) como internacional. La temática relativa a los estudios sobre la población, la historia de la demografía regional, con una cantidad de 2 publicaciones - $2 \%$ del total- (uno de los títulos es la elaboración de un mapa de densidad de la población para el sur occidente del país durante el periodo de 1843 a 1870 y el otro una investigación sobre la demografía en el Valle durante el siglo XX), se ha desarrollado débilmente en el panorama de la investigación histórica sobre la economía regional.

Igual panorama transcurre con los estudios sobre la historia del crédito (de las instituciones, de los movimientos de capitales, de los préstamos, los bancos, los aspectos monetarios, etc.) con solo un -interesante por demás- libro sobre el crédito y la economía vallecaucana en el siglo XIX (concretamente para el periodo de 1851 a 1880), que logra presentar un panorama general del funcionamiento de las formas de crédito presentes en una economía poco desarrollada como la del Valle en la segunda mitad del siglo XIX, y otro titulo, una reseńa crítica sobre este mismo libro. Fuera de estos dos títulos, no cuenta con más estudios que investiguen esta temática, que con un cultivo más acucioso y permanente puede brindar muchos frutos en el conocimiento de los aspectos de la historia del crédito en el Valle del Cauca.

De igual forma se han realizado investigaciones en otros aspectos agrupadas bajo la categoría de Otros temas que, por no poseer un número alto de publicaciones, no fueron clasificadas aparte. Aquí se encuentran dos publicaciones, una tiene como objeto de estudio las transformaciones paisajísticas en la zona plana del Valle del Cauca ocurridas a través del siglo XIX y XX, y otro trabajo, pionero en el terreno de los estudios históricos sobre la economía regional, que pretende brindar una serie de elementos preliminares para el estudio de la inversión extranjera en el Valle del Cauca en el siglo XX. El desarrollo de aspectos y problemas no tradicionales en el espectro temático de la historiografía económica puede promover una oxigenación en el desarrollo de esta historiografía sectorial, vinculando nuevos problemas, nuevos objetos de análisis, nuevas perspectivas y fuentes que contribuyan a la superación del notable interregno por el que transcurre hoy la producción de conocimiento sobre la historia económica de la región. Estas perspectivas se deben desarrollar a la par del trabajo de consolidación de los problemas y procesos ya investigados y de los que tienen poca presencia, como la historia del comercio, que cuenta solo con una publicación, en donde se analiza la formación y funcionamiento del mercado regional en el sur occidente del país durante los primeros años de la Republica. El análisis de estos procesos es fundamental para el desarrollo de la escritura de la historia económica, porque el estudio de la formación de mercados locales y regional puede aportar luces sobre aspectos y problemas fundamentales de la historia económica regional. 
Para un total de 132 publicaciones, el panorama que muestra la historiografía económica sobre el Valle del Cauca, en cuanto a su distribución temática se refiere, revela una concentración hacia el estudio e investigación en las áreas de la historia empresarial y la historia local, una diversificación en los temas y problemas objetos de análisis, con niveles cuantitativos -y lógicamente cualitativos- dispares, desiguales, unos más desarrollados que otros respecto al número de obras por cada tema.

\section{Siglos-periodos estudiados}

La historiografía económica sobre el Valle del Cauca presenta una tendencia general, en cuanto a temporalidad se refiere, a los análisis e investigaciones enmarcados en cortos y breves periodos de duración, de alrededor de unos tres, cuatro o cinco decenios que intentan abordar un temporalmente acotado y parcializado objeto de estudio. La perspectiva historiográfica que privilegian los estudios sobre la historia económica del Valle del Cauca es afín al historicismo, al estudiar los procesos económicos en su reducida singularidad. En el caso de que los análisis amplíen su tiempo de investigación, por ejemplo a un siglo, en realidad constituyen trabajos que se concentran en un periodo específico alrededor de cinco o seis décadas.

Tabla No. 7. Siglos-periodos

\begin{tabular}{|c|c|c|c|c|}
\hline Siglos & XIX & XX & XIX-XX & Total publicaciones \\
\hline Total & 42 & 66 & 24 & 132 \\
\hline Porcentaje & $32 \%$ & $50 \%$ & $18 \%$ & $100 \%$ \\
\hline
\end{tabular}

Fuente: Obras de la historiografía económica acerca del Valle del Cauca. Siglos XIX-XX.

Al observar el número de publicaciones dedicadas a cada uno de los siglos objeto de estudio -42 para el siglo XIX y 66 para el siglo XX- (Tabla No. 7), se comprueba que representan el $82 \%$ del total de publicaciones, mientras que los estudios dedicados a abordar los dos siglos -XIX y XX con una cantidad de 24- representan tan solo el 18\% del total; es decir, se demuestra que la tendencia general es a los estudios monográficos dedicados a investigar cortos o medianos periodos, siendo minoritarios los estudios que tratan de abarcar un periodo basto y amplio. De igual manera a lo evidenciado para los siglos XIX y XX, no existen trabajos que intenten conectar el periodo colonial con el periodo republicano del siglo XIX y el siglo XX, ausencia que no permite contar con un conocimiento temporal general, que muestre los cambios y permanencias ocurridas en el 
transcurso de esos siglos. Así, la historiografía económica se caracteriza por estudios parcializados que no intentan -porque no se lo proponen ${ }^{24}$ conectar diferentes temporalidades - por ejemplo entre los siglos XIX y XX-, ${ }^{25}$ no permitiendo así una visión panorámica que interconecte los diferentes procesos de la historia económica regional.

El siglo que concentra la mayor parte de las investigaciones es el siglo XX al contar con 66 estudios -el 50\% del total-, cifra que incluye una porción de estudios de coyuntura económica, que en términos estrictos y rigurosos no contienen ni emplean una perspectiva diacrónica ni un tratamiento histórico de la economía regional, incluidos por ser los únicos estudios sobre temáticas y periodos concretos para las últimas décadas el siglo XX. Los estudios sobre este siglo se concentran alrededor del análisis de cinco, seis - principalmente- y siete décadas, aunque es significativo el número de obras enfocados en análisis de coyuntura que van desde los cuatro, cinco y ocho ańos al de una década o dos. No obstante, en contraste con el siglo XIX, se encuentra una buena proporción de estudios que pretenden abordar el siglo cronológico en su totalidad. La mayoría de estudios, aunque algunos abordan de manera general todo el siglo, tienden a concentrarse en las primeras décadas de este, enfocados en el desarrollo económico-social, el proceso de industrialización y modernización de la región, y en los mediados de siglo, situación que se invierte, evidentemente, cuando nos acercamos cada vez mas a finales de siglo XX, para el cual existen solo trabajos realizados por economistas centrados en la metodología regional y la perspectiva de los análisis de coyuntura (Véase Guzmán, 2003). De esta manera, la historiografía solo logra obtener una serie aislada de problemas, aspectos, temáticas y procesos sin conexión ni intermediación alguna, lo que no permite una comprensión y explicación coherente y articulada de la historia económica de los siglos XIX y XX.

El siglo XIX, con un 32\% del total de publicaciones -42 obras,$-{ }^{26}$ es la categoría que sigue en importancia en cuanto a cantidad de publicaciones, importante número de investigaciones dedicadas a periodos de este siglo. En realidad, y esto es una hipótesis aún no desarrollada, de los siglos XIX y XX es el primero de estos el que cuenta con los mejores trabajos y es el siglo, en términos generales, para el que se posee el mayor acumulado de conocimiento.

24 Además de esta razón, puede ser que la perspectiva historiográfica dominante en los estudios históricos de la economía de la región (¿historicista, eventual, coyunturalista, empirista? Solo lo sabremos indagando de manera más profunda sobre los problemas, las temáticas y las perspectivas de las investigaciones) imponga la adopción de estos marcos temporales en los análisis.

25 Como se observa en la tabla, solo 24 publicaciones intentan realizar esta conexión.

26 Uno de ellos es un balance historiográfico y dos abarcan el siglo XVIII, un titulo se remonta a la colonia estudiando el desarrollo urbano de Cali, y otro sobre Japio investiga una hacienda colonial hasta el siglo XIX. 
El periodo cronológico que predomina en estas investigaciones sobre el siglo XIX oscila alrededor de las tres o cuatro décadas, periodo que reduce aún más la temporalidad objeto de estudio en comparación al siglo XX, siendo muy escasos los que se dediquen al examen de todo el siglo. ${ }^{27}$ Esto confirma la tendencia descrita al coyunturalismo (anecdotismo, historicismo) de los estudios acerca de la economía regional. La generalidad de los trabajos se concentra en las primeras décadas de la vida republicana y en las décadas posteriores a la fecha de abolición de la esclavitud ${ }^{28}$-pocos son los que se dedican a las últimas décadas del siglo-, aunque de manera general hay una distribución equilibrada en el tratamiento cronológico de todo el siglo con base en la adopción de parciales periodos de estudio.

La categoría de los siglos XIX y XX es la menos desarrollada en el conjunto de los estudios histórico-económicos sobre la región, dada la tendencia arriba descrita hacia las investigaciones centradas en cortos y parciales periodos históricos de investigación, porque como se sustentaba la proporción de estudios dedicados a interconectar los procesos de estos dos siglos de manera que nos propongan una visión relativamente total del desenvolvimiento económico es aún modesta. Esto se acentúa al indicar que muchos de los trabajos que abarcan estos dos siglos en realidad solo lo realizan de manera aproximada y generalizada, haciendo énfasis en algún -o algunos- subperiodo de estos dos siglos. Si bien, para presentar estas hipótesis, este trabajo se basa en términos estrictamente cuantitativos, un balance historiográfico que atienda y examine de manera más profunda los contenidos de las obras podría someter a prueba algunas de la hipótesis aquí presentadas respecto al poco desarrollo de la investigación sobre la región en lo que concierne a trabajos que superen la perspectiva localista, parcializada, coyunturalista, que brinden reconstrucciones históricas que permitan un conocimiento, comprensión y explicación general-total rigurosa de la historia económica a lo largo de estos dos siglos, al señalar sus vacíos, puntos nodales, problemáticas centrales y ritmos fundamentales.

Muchos de estos estudios sólo abarcan un periodo cronológico de más o menos un siglo, cuando no menos, que comprende o se ubica entre los dos siglos -de 1850 a 1950 , de 1885 a 1930 o de 1864 a $1964-$, además de otros análisis que si bien pretenden abarcar el conjunto de los dos siglos, lo hacen de manera muy precaria y parcial, enfocándose en un periodo especifico de estos.

27 Las pocas excepciones de estos trabajos generales sobre todo el siglo XIX son los trabajos recopilados en la colección, bajo la dirección de German Colmenares, Sociedad y economía en el Valle del Cauca, los cuales ofrecen una cobertura relativamente secuencial, iniciando el estudio de la independencia hasta la década de 1880 abarcando temas como las reformas económicas, el crédito, conflictos e impacto de las crisis en la región.

28 Donde se abordan los procesos de formación de clases sociales, la fuerza de trabajo, el crédito y el desarrollo económico, la creación de las comunidades campesinas y procesos de poblamiento. 
De esta manera, la escritura de la historia económica del Valle del Cauca entre los siglos XIX y XX solo cuenta con uno o dos trabajos que brindan una visión relativamente general de los procesos económicos centrales para comprender y explicar la historia económica de la región. Sí la historiografía económica espera seguir desarrollándose de manera fructífera y positiva debe empezar a establecer relaciones entre los trabajos monográficos que existen -y estén por realizar-con la construcción de investigaciones que integren perspectivas -tanto cronológicas, espaciales, y temáticas como metodológicas y teóricas- de carácter mas amplio y general -con rigurosidad y sólida sustentación empírica y teórica- que brinden cada vez más, mediante la creciente complejización de los problemas y procesos de la historia económica, estudios que permitan avanzar en el conocimiento, comprensión y explicación de la problemática económica regional.

\section{Espacios cubiertos}

La historiografía económica sobre el Valle del Cauca presenta una tendencia general, en cuanto a cubrimiento de espacio geográfico se refiere, centrada en los análisis generales, definidos como los estudios que en la delimitación de su objeto pretenden brindar una visión espacial y geográfica general. ${ }^{29}$ La preponderancia de este tipo de análisis enmarcados en esta perspectiva es indicador del esfuerzo por ofrecer panoramas relativamente amplios que permitan hacerse una idea de la historia económica de la región en su totalidad espacial.

Tabla No. 8. Espacios

\begin{tabular}{|c|c|c|c|c|}
\hline Espacios & Generales & Cali & Otros & $\begin{array}{c}\text { Total } \\
\text { publicaciones }\end{array}$ \\
\hline Total & 84 & 25 & 23 & 123 \\
\hline$\%$ & 64 & 19 & 17 & 100 \\
\hline
\end{tabular}

Fuente: Obras de la historiografía económica acerca del Valle del Cauca. Siglos XIX-XX.

Con un número de publicaciones de 84 títulos, un 64\% del total, esta categoría ha alcanzado un relativo desarrollo en comparación con las otras categorías tenidas en cuenta. En estos análisis se hallan estudios que ofrecen desde panoramas que integran varias temáticas y problemas (sobre el desarrollo,

29 En general el uso que hace la historiografía económica del concepto región es muy laxo y amplio, con poca reflexión teórica y metodológica. Por esta razón la presente polivalencia en el manejo del concepto, lo cual nos lleva a nosotros a no adoptar una definición, con el objetivo de incluir las variadas acepciones y perspectivas que se encuentran sobre la región del Valle del Cauca. 
"modernización" y el desenvolvimiento económico, la configuración moderna de la región, etc.) y brindan una visión total de la historia económica -en cuanto a temas se refiere-, hasta análisis espaciales generales sobre aspectos y problemas particulares de la economía regional durante los siglos XIX y XX, como estudios sobre los empresarios y las empresas vallecaucanas, acerca del sector azucarero y cafetero, la historia demográfica, agraria y del campesinado, la configuración de las clases sociales y la fuerza de trabajo, entre otras. No obstante, muchos de los estudios que pretenden insertarse en análisis espaciales generales del Valle del Cauca, en realidad corresponden a análisis que, a partir de un espacio particular (Cali o determinada localidad del Valle), generalizan el conocimiento acerca de la región, debido a un evidente defecto metodológico en la definición del objeto de estudio -en cuanto a la unidad espacial objeto de análisis- observado en las ambigüedades y diferentes criterios con que se pretende abordar el estudio de la región. Esta situación debe subsanarse, en investigaciones posteriores, con panoramas que integren la diversidad regional (en todos sus aspectos, económicos, geográficos, etc.) y con evitar incurrir en generalizaciones particularistas de la historia económica del Valle del Cauca.

Los estudios que toman unidades espaciales más delimitadas constituyen el otro $36 \%$ del total de las publicaciones -48 títulos-, se han dividido bajo el criterio de dos categorías; una que agrupa los trabajos que se enfocan en el territorio de Cali, y una denominada otros donde se integran estudios que se dedican a municipios o localidades de la región como Yumbo, Palmira, Candelaria, Tulúa, Buenaventura, etc. Para el municipio de Cali la historiografía económica cuenta con un total de 25 publicaciones -el $19 \%$ del total- y 23 títulos para la categoría de otros, el $17 \%$ del total. El municipio de Cali, al constituir el centro y la unidad más importante de la región, logra el mayor número de publicaciones dedicadas a espacios locales. Esto constituye un adelanto en el conocimiento de uno de los espacios económicos más importantes, en temáticas y problemas como la historia del desarrollo urbano, los ejidos, la formación de las clases sociales, la industrialización, las empresas y los empresarios, entre otros. De similar manera existe una importante producción dedicada a otras localidades o espacios que alcanza 23 publicaciones, nivel que se ha logrado debido al lento descentramiento de los estudios alrededor del municipio de Cali. En esta categoría se desarrollan más los estudios generales, en cuanto a temas concierne, de localidades como Japio, Cerrito, Buga, Candelaria, Palmira, Yumbo, Restrepo, Bolívar, Buenaventura, Bugalagrande, que intentan proponer visiones panorámicas de la historia económica de los municipios, en 
contraste con los pocos estudios dedicados a temáticas o problemas específicos del desenvolvimiento económico de estos. ${ }^{30}$ Sobresale el gran porcentaje de libros publicados (cerca de la mitad) que corresponden a estudios elaborados sobre historia económica de algún municipio del Valle del Cauca, en donde destacan las historias de empresas, particularmente de ingenios azucareros.

Este panorama es favorable para el desarrollo de la historiografía económica acerca del Valle del Cauca, al presentar un relativo equilibrio en el tratamiento de los diferentes espacios y una visión espacial general de la historia económica. No obstante, aún falta un desarrollo más dinámico en cuanto al estudio de municipios diferentes al de Cali, porque aunque su número es significativo, aún es insuficiente para el proceso de lograr un conocimiento del diverso desarrollo espacial de la historia economía regional, al igual que es necesaria la superación de la tendencia a lograr la generalización a partir de un solo espacio y no a partir de la perspectiva comparativa entre varios espacios-localidades.

\section{Conclusiones}

Después de un recorrido por algunos aspectos y características sobresalientes de la historiografía económica acerca del Valle del Cauca durante los siglos XIX y XX, se señalan algunas cuestiones a modo de conclusión. El panorama elaborado indica apenas un orden de atención temática, espacial, y temporal. La investigación y escritura de la historia económica, después de pasados cuatro decenios desde su surgimiento en el seno de los estudios históricos sobre la región, ha logrado un desarrollo importante en términos de aportes al conocimiento del desenvolvimiento de la economía regional durante los siglos XIX y XX, al consolidar un acumulado de publicaciones sobre diversas temáticas, problemáticas, periodos y espacios históricos, en el que han intervenido diferentes autores y disciplinas.

No obstante, al considerar cada uno de los dos siglos de la historia del Valle, es fácil percibir que están irregularmente cubiertos -temática, temporal y espacial-, bien sea porque existen subperiodos que han sido examinados de modo escaso o porque subsisten vacíos en cuanto a la investigación de algunos temas y problemas pertinentes para su comprensión. Temáticamente existe una concentración hacia los estudios sobre la historia empresarial y de empresarios, además de una exigua investigación sobre algunos temas-problemas fundamentales. Temporalmente los estudios se concentran en periodos de alrededor de cinco décadas promedio, resultando escasos los trabajos desde una perspectiva de larga

30 Entre ellos encontramos estudios sobre las haciendas, los empresarios, la industrialización y el desarrollo de la agroindustria. 
duración. Espacialmente los estudios se concentran en los municipios de Cali y Yumbo, en la zona central plana del Valle, con supremacía de los análisis generales sobre el espacio regional. Las zonas del norte del Valle adolecen de estudios, aun cuando se han desarrollado en estas zonas importantes renglones productivos y comerciales. Estas falencias aunadas no permiten establecer una periodización regular y general en el análisis y explicación de los ritmos, continuidades y discontinuidades de la historia económica de la región.

La historiografía económica necesita de una postura que no desprecie la teoría ni las circunstancias específicas. Ciertamente, y salvo unas excepciones, lo que parece experimentarse hoy es una inconveniente separación entre esfuerzos de síntesis que ignoran los fenómenos puntuales y una proliferación de estudios parciales, muchos de excelente calidad, pero que dependen más de la disponibilidad de información que de la relevancia del problema. Quizás esta separación derive, al menos en parte, de la falta de hipótesis relevantes que establezcan rumbos productivos para la investigación; de una perspectiva teórico metodológica explicita que guíe un conjunto de problemas y temáticas que pasen del plano reconstructivo -descriptivo- al plano comprensivo y explicativo. Es necesario que la escritura de la historia económica siga avanzando en el camino de una mayor y real institucionalización que le permita tener continuidad y el apoyo requerido para la investigación, lo que redundará y posibilitará la consolidación no solo de esta historiografía sectorial sino del conjunto de la disciplina histórica, lo cual en definitiva sólo se resolverá cuando se construya y consolide un campo de la historiografía económica sobre el Valle del Cauca fuerte y solidó, que trabaje para superar el estancamiento diagnosticado en los últimos años.

Esbozada en conjunto, la escritura de la historia económica, mirada desde la perspectiva de la información e hipótesis construidas, esta constituida por un conjunto de piezas que deben ser, unas completadas y otras refinadas de modo que se pueda obtener, tanto temporal, espacial como temáticamente, un cuadro más completo y más coherente del desenvolvimiento económico regional, al subsanar los problemas que aún subsisten. Se deben empezar a realizar investigaciones que apunten al establecimiento de un cuadro total para, sobre esta nueva base, avanzar en el estudio e investigación de nuevos problemas y perspectivas que sin duda surgirán como producto del desarrollo de los estudios sobre la historia económica regional; y recordar, con Fernand Braudel:

La historia es el cuento de nunca acabar, siempre está haciéndose, superándose. Su destino no es otro que el de todas las ciencias humanas. No creo, por lo tanto, que los libros de historia que escribimos sean validos durante decenios y decenios. No hay ningún libro escrito de una vez por todas, como ya sabemos. 
Y Joseph Fontana:

Recuperar la identidad del trabajo en el campo de la historia económica significa recordar que esta no es ni una rama de la ciencia económica, ni una variedad temática de la historia, [...] sino, en todo caso, un modo de hacer historia.

\section{Bibliografía}

-Aguirre rojas, Carlos, La historiografía en el siglo XX. Historia e historiadores entre 1848 y 2005, España, Montesinos, 2004.

-Aróstegui Julio, La investigación histórica: teoría y método, Barcelona, Crítica, 1995.

-Bejarano, Jesús Antonio, Historia Económica y Desarrollo: La historiografía económica sobre los siglos XIX y XX en Colombia, Bogota, Cerec, 1994.

-Bourdieu Pierre, “¿Qué es hacer hablar a un autor? A propósito de Michel Foucault", en: Capital cultural, escuela y espacio social, Argentina, Siglo XXI, 2003.

-Bourdieu, Pierre, "El campo científico", en: Intelectuales politica y poder, Argentina, Eudeba, 1999.

-Fontana, Joseph, Historia: Análisis del pasado y proyecto social, Barcelona, Critica, 1999.

-Guzmán, Álvaro, et al. Cuatro ensayos de coyuntura: Valle y Cauca a fines de siglo XX, Santiago de Cali, Universidad del Valle, 2003.

-Londoño Motta, Jaime Eduardo, "El modelo de colonización antioqueña. Un balance historiográfico", en: Revista Fronteras de la historia, Vol. 7, Bogotá, ICAH, 2002. 
-Londońo Motta, Jaime Eduardo, "La historia económica del Valle del Cauca" en: Región. Revista del centro de estudios regionales, No. 2, Universidad del Valle, 1994.

-Londoño Motta, Jaime Eduardo, MAC: Empresa y familia, medio siglo de energía, Universidad Icesi, Cali, 2007.

-Mejía Prado, Eduardo, "La producción historiográfica sobre el poblamiento del Valle del Cauca 1800-1874”, en: Región. Revista del centro de estudios regionales, No. 7, Universidad del Valle, 1999.

- Meisel Roca, Adolfo, "Los estudios sobre historia económica de Colombia a partir de 1990: Principales temáticas y aportes", en: Cuadernos de Historia Económica y Empresarial, No. 13, Banco de la Republica, 2005.

-Ordónez Burbano, Luís Aurelio, "La historia empresarial en el Valle y el Cauca”, en: Grupo de Historia Empresarial: Las regiones y la historia empresarial, Universidad EAFIT, Medellín, 2004.

-Samuel, Raphael, Ed, Historia popular y teoría socialista, Barcelona, Crítica, 1984.

-Kalmanovitz, Salomón, "La Clíometria y la historia económica institucional: Reflejos latinoamericanos", Historia Crítica. Revista del Departamento de Historia de la Universidad de los Andes, Bogota, 2005.

-Valencia Llano, Alonso, "Los apoyos institucionales en el desarrollo historiográfico del suroccidente colombiano", en: Región: Revista del centro de estudios regionales, No. 9, Universidad del Valle, 2001.

-Vásquez, et al., Historia y espacio. Revista de estudios históricos regionales, Santiago de Cali, Universidad del Valle, No. 1., 1979. 